\title{
Postoperative Respiratory Compromise following Cesarean Birth: The Impact of Obesity and Systemic Opioids
}

\author{
Jessica L. Walker, MD ${ }^{1}$ Jacquelyn $\mathrm{H}$. Adams, MD ${ }^{1}$ \\ Kathleen M. Antony, MD, $\mathrm{MSCl}^{10}$ \\ ${ }^{1}$ Division of Maternal-Fetal Medicine, Department of Obstetrics and \\ Gynecology, University of Wisconsin - Madison, Madison, Wisconsin \\ 2 Department of Biostatistics and Medical Informatics, University of \\ Wisconsin, Madison, Wisconsin \\ ${ }^{3}$ Department of Anesthesiology, Madison Anesthesiology \\ Consultants, Madison, Wisconsin
}

Aimee T. Broman, MA $^{2}$ Peter G. Pryde, MD $^{3}$
AJP Rep 2022;12:e1-e9.

\begin{abstract}
Address for correspondence Kathleen M. Antony, MD, MSCl, Division of Maternal-Fetal Medicine, Department of Obstetrics and Gynecology, School of Medicine and Public Health, University of Wisconsin - Madison, 202 South Park Street, Madison, WI 53715 (e-mail: kantony@wisc.edu).
\end{abstract}

\begin{abstract}
Keywords

- obesity

- analgesia

- obstetrics

- opioids

- postoperative respiratory compromise

- cesarean

Objective The aim of this study was to measure the effect of obesity and systemic opioids on respiratory events within the first 24 hours following cesarean.

Methods Opioid-naive women undergoing cesarean between January 2016 and December 2017 were included in this retrospective cohort study. The primary outcome was the proportion of women experiencing at least one composite respiratory outcome (oxygen saturation less than $95 \%$ lasting $30+$ seconds or need for respiratory support) within 24 hours of cesarean. The impact of obesity and total systemic opioid dose in 24 hours (measured in morphine milligram equivalents [MMEs]) on the composite respiratory compromise outcome were evaluated.

Results Of 2,230 cesarean births, 790 women had at least one composite respiratory event. Predictors of the composite respiratory outcome included body mass index (BMI) as a continuous variable (odds ratio $=1.063$ for every one unit increase in BMI [95\% confidence interval $(\mathrm{Cl}): 1.021-1.108], p=0.003$ ), and $\mathrm{MME}$ (odds ratio $=1.005$ [95\% Cl: 1.002-1.008], $p=0.003$ ), adjusting for magnesium sulfate use. The interaction between obesity and opioid dose demonstrated an odds ratio of 1.000 (95\% Cl: 0.999-1.000, $p=0.030$ ).

Conclusion The proportion of women experiencing respiratory events following cesarean birth increases with the degree of obesity and opioid dose.
\end{abstract}

\section{Key Points}

- Respiratory events increase with obesity.

- Respiratory events increase with systemic opioid use.

- Odds ratio of respiratory events is $1.063 /$ unit BMI increase.

received

October 19, 2020 accepted after revision October 8, 2021
DOI https://doi.org/ $10.1055 / \mathrm{s}-0041-1741539$. ISSN 2157-6998. (c) 2022. The Author(s).

This is an open access article published by Thieme under the terms of the Creative Commons Attribution-NonDerivative-NonCommercial-License, permitting copying and reproduction so long as the original work is given appropriate credit. Contents may not be used for commercial purposes, or adapted, remixed, transformed or built upon. (https://creativecommons.org/ licenses/by-nc-nd/4.0/)

Thieme Medical Publishers, Inc., 333 Seventh Avenue, 18th Floor. New York, NY 10001, USA 
Obesity is associated with adverse pregnancy outcomes including cesarean birth and anesthesia-related maternal deaths. $^{1-11}$ While the risk of obesity-related respiratory depression and its relationship with postoperative opioid use is well documented in the general surgical literature, ${ }^{12-23}$ documentation in obstetric literature has been limited. ${ }^{24}$ One study identified no instances of respiratory depression among postcesarean women receiving morphine, ${ }^{24}$ but the route of administration was neuraxial, which has been found to rarely be associated with clinically relevant respiratory depression. ${ }^{25}$ Reviews and recommendations that address the risk of respiratory depression from systemic opioids among postcesarean women with obesity often extrapolate data from nonobstetric postoperative populations. ${ }^{26-29}$

Respiratory events can occur across a spectrum of severity, ranging from mild respiratory depression to life-threatening hypoxia. The aim of our study was to measure the proportion of women experiencing at least one composite respiratory event in the first 24 hours after cesarean birth, and to evaluate the effect of obesity (by body mass index [BMI] class) and opioids on the occurrence of these respiratory events. We chose to focus on maternal respiratory events during the first 24 hours because this has previously been shown to be the time period of highest risk for a respiratory event to occur as a result of opioid use. ${ }^{30}$ Our hypothesis was that postcesarean respiratory events would increase with both increasing BMI and increasing opioid dose.

\section{Materials and Methods}

This study was a retrospective cohort study of all cesarean births that occurred from January 1, 2016, through December 31, 2017, at a single institution, UnityPoint Health Meriter in Madison, WI. UnityPoint Health - Meriter is affiliated with the University of Wisconsin School of Medicine and Public Health and is the clinical obstetrics site for the Department of Obstetrics and Gynecology. Institutional Review Board (IRB) approval was obtained prior to data collection (UnityPoint Health - Meriter IRB\#: 2018-003). We used a query of the hospital's birth database (PeriData. Net, Ancilla Partners, Inc., Milwaukee, WI) to generate a list of all cesarean births that occurred during 2016 to 2017. Data entry into PeriData are performed manually via review of information submitted by parents and the hospital's electronic health record. PeriData are audited by nursing perinatal data coordination staff and data were extracted by Kathy Gollmar. We simultaneously queried the electronic health record system (Epic, Hyperspace 2017, Epic Systems Corporation, Verona, WI) to compile clinical data from the first 24 hours following cesarean birth. Data in the electronic health record system accurately document vital signs, medication administration times and doses, and medical interventions at the point of clinical care; data were extracted by Walter Bredl and Ruth Hallquist.

Inclusion criteria for the study necessitated that women had undergone a cesarean birth. Inclusion in the obesity analysis required a prepregnancy BMI be listed in the medical record. Excluded from analysis were women who required intubation postcesarean for indications unrelated to the exposures of interest (e.g., sepsis or following massive transfusion) and women with opioid use disorder identified by individual review of the electronic health record including the intake history and physical examination, the "problem list," and medications prescribed. Additional data points include the maternal height and weight, both prepregnancy and at admission for delivery, maternal age, parity, race, ethnicity, smoking status, gestational age at delivery, medical comorbidities (including obstructive sleep apnea and asthma), and obstetric outcomes. Medical comorbidities and obstetric outcomes, such as hypertensive disorders of pregnancy and pregestational and gestational diabetes, were diagnosed as per the definitions established by the American College of Obstetricians and Gynecologists for the years of data collection (2016-2017). ${ }^{31-33}$ A diagnosis of preeclampsia with severe features was used as a surrogate variable for magnesium sulfate use because compliance at our institution is $100 \%$ and because this is the exclusive indication for its continuous use in the postpartum time period. Indications for cesarean delivery were extracted from the electronic medical record system into the birth information database from the operative note. Intrathecal hyperbaric bupivacaine with fentanyl for spinal anesthesia and bicarbonated lidocaine with fentanyl for epidural anesthesia are the standard neuraxial analgesia regimens used at our institution. At the time of this study, our institution did not use neuraxial morphine or other long-acting hydrophilic opioids.

The primary outcome measure was the presence or absence of a composite of the following respiratory events: mild desaturation event $\left(\mathrm{SpO}_{2}\right.$ less than 95\% lasting for 30 seconds or longer); moderate desaturation event $\left(\mathrm{SpO}_{2}\right.$ less than $90 \%$ lasting for 30 seconds or longer); severe desaturation event $\left(\mathrm{SpO}_{2}\right.$ less than $85 \%$ lasting for 30 seconds or longer), documented in the electronic health record, and need for respiratory support. Respiratory support was defined as requiring any of the following: oxygen via nasal cannula, nonrebreather mask, partial nonrebreather mask, OxyMask, or Ventimask, new requirement for continuous positive airway pressure (CPAP) support, bilevel positive airway pressure, or intubation. The exact type of respiratory event or requirement for support was recorded and analyzed as secondary variables, including the requirement for "high respiratory support," which we defined as requiring any of the following: partial nonrebreather, nonrebreather, positive airway pressure, OxyMask, or Ventimasks. A significant respiratory event was characterized by a new requirement of face masks for respiratory support or presence of severe oxygen desaturation (or both). To assess for respiratory etiologies, we planned to analyze any maternal deaths.

We assessed the proportion of women having at least one composite respiratory event by prepregnancy BMI, both as a continuous variable and by BMI class as follows: nonobese $\left(\mathrm{BMI}<30 \mathrm{~kg} / \mathrm{m}^{2}\right)$, class I obesity (BMI $30-34.9 \mathrm{~kg} / \mathrm{m}^{2}$ ), class II obesity (BMI $35-39.9 \mathrm{~kg} / \mathrm{m}^{2}$ ), and class III obesity $\left(\mathrm{BMI} \geq 40 \mathrm{~kg} / \mathrm{m}^{2}\right) .{ }^{34}$ We also analyzed if the occurrence of an 
event was associated with the total systemic opioid dose administered in the first 24 hours postcesarean. This dose was calculated by converting all administered opioid doses into oral morphine milligram equivalents (MMEs) and, once converted, summing the doses into a single total MME for the 24-hour period. ${ }^{35-37}$

We observed the relationship of demographic variables and respiratory measures with BMI and opioid use in crosstabulations to observe if these might be associated with either outcome. We used Fisher's exact and chi-square tests to determine if there was an association between categorical measures and responses, and analysis of variance F-test to determine association between categorical measures and continuous responses. An a priori power analysis was performed using rates of opioid-related adverse respiratory events described in the nonobstetric literature. We assumed a rate of opioid-related adverse respiratory events of $4.2 \%^{23}$ (from a nonobese, nonobstetric population) and an odds ratio (OR) of 1.05 (range in the literature of 1.01-1.22) for increased risk of an opioid-related adverse respiratory event. Our estimated ratio of obese to nonobese was 1.3 (which approximates our institution's ratio of cesarean birth among obese women to cesarean birth among nonobese women in 2016). Using these estimates, a sample size of 1,249 subjects would be required to achieve $80 \%$ power to detect a $5 \%$ increase in respiratory events. To assess our secondary outcomes and due to the retrospective nature of this study, we included all patient charts who met the inclusion criteria.

We assessed the association of opioid dose on the presence of a respiratory event adjusting for BMI in logistic regression models adding MME, BMI, and magnesium sulfate use as potential predictors of the composite respiratory outcome. We also intended to observe the relationship of obstructive sleep apnea on respiratory events. Respiratory events included the presence or absence of any of the following: composite respiratory outcome, oxygen desaturation, use of a nonrebreather mask, and high respiratory support. We performed statistical calculations using R(Version 3.5.1. Released 2018. R Foundation for Statistical Computing, Vienna, Austria). We report our findings according to Strengthening The Reporting of Observational Studies in Epidemiology. ${ }^{38}$

\section{Results}

A total of 2,264 cesarean births occurred at our institution during 2016 to 2017. Five were excluded due to postcesarean intubation for medical indications. Twenty-nine women were excluded due to opioid use disorder or buprenorphine or methadone use. Six women lacked BMI data and were not included in the Fisher's exact test or the chi-square test of association, but they were included in other analyses. A total of 2,230 births were included.

Demographic factors associated with BMI included race and age $(p<0.001,-$ Table 1$)$. Those with any type of hypertensive disorder were more likely to have higher BMI than those without $(p<0.0001)$; diabetes was highly associated with higher BMI $(p<0.001)$. Sixteen women had a previous diagnosis of obstructive sleep apnea identified in the medical record, the majority of whom had higher BMI (association of sleep apnea and obesity, $p<0.001$ ). Those with asthma or who smoked were more likely to be obese than those who did not have asthma or smoke $(p=0.004$ and 0.001 , respectively). The mean MME dose was 103.0 (standard deviation [SD] 32.1) for women without obesity, 105.5 (SD 36.4) for class I obesity, 108.1 (SD 32.8) for class II obesity, and 109.4 (SD 32.3) for class III obesity $(p=0.021)$. There were no maternal deaths.

Demographic factors associated with higher doses of opioid dose included age $(p<0.001)$, obesity $(p=0.026)$, and smoking status $(p<0.001) \quad(-$ Table 2$)$. Obstetric characteristics such as use of general anesthesia $(p<0.001)$, planned versus unplanned cesarean $(p<0.001)$, mode of anesthesia $(p<0.001)$, and hypertensive disorders of pregnancy $(p<0.001)$ were also associated with higher opioid dose.

A total of 794 composite respiratory events were observed across all women (-Table 3). The proportion of those with respiratory events was lowest among those with normal BMI (33\%) and higher for women with obesity (38-42\%) (Fisher's $p=0.009$ ). The majority of these respiratory events were mild, but there were also more moderate and severe respiratory events for women with obesity $(p=0.012)$. With the exception of CPAP, there were no differences in the requirement for respiratory support by BMI class nor were there increased prevalence of requiring high respiratory support. No women required intubation.

The presence of composite respiratory event was associated with opioid dose $(p=0.005,-$ Table 4$)$. The need for high respiratory support also differed by opioid dose $(p=0.012)$.

In a multivariate regression model, prepregnancy BMI $(\mathrm{OR}=1.063$ [95\% confidence interval $(\mathrm{CI})$ : 1.021-1.108], $p=0.003)$ and opioid dose (OR=1.005 [95\% CI: $1.002-$ 1.008], $p=0.003$ ) were predictors of having a composite respiratory event (-Table 5 ). A one unit increase in BMI (defined each $1 \mathrm{~kg} / \mathrm{m}^{2}$ increase) had a 1.063 higher odds of an oxygen desaturation event compared with no unit increase. There was also a modest interaction between opioid dose and $\mathrm{BMI}$ of $\mathrm{OR}=1.000$ (95\% CI: 0.999-1.000, $p=0.030$ ). Magnesium sulfate use was also a predictor of the composite respiratory outcome with an OR of 2.505 (95\% CI: 1.6873.751 ). As only 16 women had documented sleep apnea, and no interaction with this comorbidity could be assessed.

\section{Discussion}

We demonstrated there is an increased risk of respiratory compromise in the first 24 hours postcesarean birth for women with obesity and also for women receiving higher opioid doses. Of these, the majority of the episodes of respiratory compromise were mild desaturation events. While an event requiring significant respiratory support was not associated with obesity, the number of women with an event was small. Our multivariate logistic regression model demonstrated that using the linear predictors estimate, women with a BMI of $50 \mathrm{~kg} / \mathrm{m}^{2}$ would have a 3.43 times higher odds of the composite respiratory outcome than women with a BMI of $30 \mathrm{~kg} / \mathrm{m}^{2}$. While we found a significant 
Table 1 Maternal characteristics by delivery BMI

\begin{tabular}{|c|c|c|c|c|c|}
\hline \multirow[t]{3}{*}{ BMI class } & Nonobese & Class I obesity & Class II obesity & Class III obesity & \multirow[t]{3}{*}{$p$-Value } \\
\hline & $\mathrm{BMI}<30$ & BMI 30-34.9 & BMI 35-39.9 & BMI 40 or higher & \\
\hline & $n=1,528$ & $n=321$ & $n=195$ & $n=186^{\mathrm{a}}$ & \\
\hline Age, y (mean, SD) & $31.7(4.9)$ & $31.6(4.9)$ & $30.1(5.3)$ & $30.6(5.0)$ & $<0.001$ \\
\hline \multicolumn{6}{|l|}{ Race, $n(\%)^{\mathrm{b}}$} \\
\hline White & $1,199(78.5)$ & 247 (76.9) & $148(75.9)$ & 148 (79.6) & \multirow[t]{4}{*}{$<0.001$} \\
\hline Black or African American & $93(6.1)$ & $31(9.7)$ & $29(14.9)$ & $31(16.7)$ & \\
\hline Asian & $170(11.1)$ & $18(5.6)$ & $8(4.1)$ & $0(0)$ & \\
\hline Other & $18(1.2)$ & $5(1.6)$ & $2(1.0)$ & $3(1.6)$ & \\
\hline Hispanic ethnicity & $115(7.5)$ & $42(13.1)$ & $16(8.2)$ & $13(7.0)$ & 0.024 \\
\hline MME dose (mean, SD) & $103(32.1)$ & $105(36.4)$ & $108(32.8)$ & $109(32.3)$ & 0.021 \\
\hline Parity $\geq 1, n(\%)$ & $1,047(68.5)$ & $235(73.2)$ & $127(65.1)$ & $131(70.4)$ & 0.224 \\
\hline \multicolumn{6}{|l|}{ Cesarean indication, $n(\%)^{c}$} \\
\hline Planned & $908(59.4$ & $199(62.0)$ & $110(56.4)$ & $104(55.9)$ & 0.470 \\
\hline Unplanned & $626(41.0)$ & $126(39.3)$ & $88(45.1)$ & $91(48.9)$ & 0.101 \\
\hline \multicolumn{6}{|l|}{ Anesthesia mode, $n(\%)^{d}$} \\
\hline Spinal & $971(63.5)$ & $211(65.7)$ & $117(60.0)$ & $112(60.2)$ & \multirow[t]{3}{*}{0.759} \\
\hline Epidural & $498(32.6)$ & $96(29.9)$ & $69(35.4)$ & $67(36.0)$ & \\
\hline General & $48(3.1)$ & $13(4.0)$ & $8(4.1)$ & $7(3.8)$ & \\
\hline \multicolumn{6}{|c|}{ Medical and obstetric comorbidities, $n(\%)$} \\
\hline Hypertension $^{\mathrm{e}}$ & $233(15.2)$ & $78(24.3)$ & $60(30.8)$ & $87(46.8)$ & $<0.001$ \\
\hline Diabetes & $147(9.6)$ & $67(20.9)$ & $42(21.5)$ & $60(32.3)$ & $<0.001$ \\
\hline \multicolumn{6}{|c|}{ Maternal respiratory conditions, $n(\%)$} \\
\hline Asthma & $28(1.8)$ & $13(4.0)$ & $7(3.6)$ & $12(6.5)$ & 0.004 \\
\hline Smoking & $92(6.0)$ & $29(9.0)$ & $19(9.7)$ & $26(14.0)$ & 0.001 \\
\hline Sleep apnea ${ }^{f}$ & $2(0.1)$ & $3(0.9)$ & $3(1.5)$ & $7(3.8)$ & $<0.001$ \\
\hline
\end{tabular}

Abbreviations: BMI, body mass index; MME, morphine milligram equivalent; SD, standard deviation.

Notes: $p$-Values in bold font indicate statistical significance for analysis of variance, chi-square, or Fisher's exact test as appropriate.

${ }^{a}$ Six women did not have prepregnancy BMI data available.

bighty women were missing data on race, 28 on ethnicity (no significant difference for missing data by BMI).

'Some women had more than one indication for cesarean (e.g., planned repeat cesarean births occurring at an unplanned time).

${ }^{\mathrm{d} D a t a}$ on anesthesia mode was missing for 13 women.

eHypertension included chronic hypertension, gestational hypertension, preeclampsia, and eclampsia. Diabetes included both pregestational and gestational diabetes.

fOne woman with sleep apnea lacked a prepregnancy BMI.

interaction between BMI and MME dose, the OR was 1.00 with a $95 \% \mathrm{CI}$ of 0.99 to 1.00 which suggests the effect of higher BMI may be modestly protective rather than exacerbating the increased effect of higher opioid dose. Magnesium sulfate use (as a dichotomous variable) also was a predictor of the composite respiratory event with an OR of 2.5.

Our findings differ from the results of prior investigations, which were typically performed in an older population with more comorbidities. In the general surgical literature, numerous studies have discussed the compounding effect of obesity and opioid use on adverse respiratory events. ${ }^{12-23}$ Published studies in obstetric literature discuss the impact of neuraxial opioids on respiratory depression and respiratory arrest and generally confirm that the risk of respiratory depression is low. ${ }^{24,25,39-41}$ Reports on respiratory arrest in postcesarean women are limited. ${ }^{42-44}$ Here, we found a relationship between respiratory compromise and BMI, but the relationship with opioid dose was less pronounced. It is possible that opioids have a lesser effect on the obstetric population because these women are generally younger, healthier, and physiologically distinct from the broader postsurgical population, but this is speculative. Results from prior studies evaluating the effect of obesity on respiratory depression after cesarean are also mixed, ${ }^{45}$ but those that do not show an increased risk only evaluated significant respiratory depression, defined as requiring naloxone or rapid response team activation. ${ }^{24}$ While the majority of the composite respiratory events reported in this study were mild, there were also more clinically relevant respiratory events than reported elsewhere in the obstetric population. 
Table 2 Maternal characteristics by 24-hour opioid dose

\begin{tabular}{|c|c|c|c|c|}
\hline \multirow[t]{2}{*}{ 24-h morphine dose $(\mathrm{mg})$} & $0-90$ & $90-110$ & $110-415$ & \multirow[t]{2}{*}{$p$-Value } \\
\hline & $(n=829)$ & $(n=721)$ & $(n=684)$ & \\
\hline Age, y (mean, SD) & $32.0(4.9)$ & $31.2(5.0)$ & $31.0(5.1)$ & $<0.001$ \\
\hline \multicolumn{5}{|l|}{ Race, $n(\%)^{\text {a }}$} \\
\hline White & $641(77.3)$ & $568(78.8)$ & $536(78.4)$ & \multirow[t]{4}{*}{0.193} \\
\hline Black or African American & $58(7.0)$ & $61(8.5)$ & $66(9.6)$ & \\
\hline Asian & $91(11.0)$ & $58(8.0)$ & $48(7.0)$ & \\
\hline Other & $9(1.1)$ & $10(1.4)$ & $9(1.3)$ & \\
\hline Hispanic ethnicity, $n(\%)^{a}$ & $71(8.6)$ & $53(7.4)$ & $62(9.1)$ & 0.828 \\
\hline \multicolumn{5}{|c|}{ Delivery body mass index, $n(\%)^{a}$} \\
\hline$<30 \mathrm{~kg} / \mathrm{m}^{2}$ & $600(72.4)$ & $469(65.0)$ & $457(66.8)$ & \multirow[t]{4}{*}{0.027} \\
\hline $30-34.9 \mathrm{~kg} / \mathrm{m}^{2}$ & $117(14.1)$ & $105(14.6)$ & $99(14.5)$ & \\
\hline $35-39.9 \mathrm{~kg} / \mathrm{m}^{2}$ & $57(6.9)$ & $71(9.8)$ & $67(9.8)$ & \\
\hline $40 \mathrm{~kg} / \mathrm{m}^{2}$ or higher & $52(6.3)$ & $75(10.4)$ & $59(8.6)$ & \\
\hline Parity $\geq 1, n(\%)$ & $584(70.4)$ & $476(66.0)$ & $483(70.6)$ & 0.098 \\
\hline \multicolumn{5}{|l|}{ Cesarean indication, $n(\%)^{\mathrm{b}}$} \\
\hline Planned & $529(63.8)$ & $393(54.5)$ & $400(58.5)$ & $<0.001$ \\
\hline Unplanned $^{\mathrm{b}}$ & $304(36.7)$ & $337(46.7)$ & $294(43.0)$ & $<0.001$ \\
\hline \multicolumn{5}{|l|}{ Anesthesia mode, $n(\%)^{c}$} \\
\hline Spinal & $583(70.3)$ & $417(57.8)$ & $410(59.9)$ & \multirow[t]{3}{*}{$<0.001$} \\
\hline Epidural & $232(28.0)$ & $278(38.6)$ & $225(32.9)$ & \\
\hline General & $11(1.3)$ & $18(2.5)$ & 47 (6.9) & \\
\hline \multicolumn{5}{|c|}{ Medical and obstetric comorbidities, $n(\%)$} \\
\hline Hypertension $^{\mathrm{d}}$ & $138(16.6)$ & $155(21.5)$ & $167(24.4)$ & $<0.001$ \\
\hline Diabetes & $115(13.9)$ & $107(14.8)$ & 95 (13.9) & 0.831 \\
\hline \multicolumn{5}{|l|}{ Maternal respiratory conditions } \\
\hline Asthma $^{a}$ & $18(2.2)$ & $19(2.6)$ & $23(3.4)$ & 0.197 \\
\hline Smoking & $41(4.9)$ & $50(6.9)$ & $74(10.8)$ & $<0.001$ \\
\hline Sleep apnea & $4(0.5)$ & $5(0.7)$ & $7(1.0)$ & 0.441 \\
\hline
\end{tabular}

Abbreviation: SD, standard deviation.

Note: $p$-Values in bold font indicate statistical significance for analysis of variance, chi-square, or Fisher's exact test as appropriate.

${ }^{a}$ Seventy-nine women were missing data on race, 28 on ethnicity, 6 on body mass index, 2 on asthma (no significant difference for missing data by opioid dose).

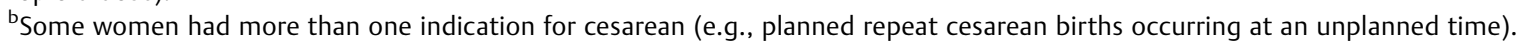

'Data on anesthesia mode were missing for 13 women.

${ }^{\mathrm{d} H y p e r t e n s i o n}$ included chronic hypertension, gestational hypertension, preeclampsia, and eclampsia. Diabetes included both pregestational and gestational diabetes.

Investigating only moderate and severe events $\left(\mathrm{SpO}_{2}<90 \%\right)$, here we report 41 events among 2,230 births for a rate of $184 / 10,000$; in the literature, among women receiving neuraxial opioids such events occur in 1.08 to $1.63 / 10,000$ cases. ${ }^{25}$ Thus, we observed at least 112 times more moderate to severe respiratory events than would be expected with neuraxial opioids. The doses of systemic opioids utilized in our population is also higher than reported elsewhere. ${ }^{46}$

The results of our study have several important clinical practice implications. Many hospitals already have increased respiratory monitoring of postoperative women with obesity, but this is not standardized. ${ }^{41}$ This study also has impli- cations regarding the safety and the intensity of postoperative monitoring when using systemic opioids versus neuraxial opioids as a primary strategy for postcesarean analgesia. Our institution opted for systemic opioids because prior recommendations for respiratory monitoring following neuraxial hydrophilic opioids were burdensome to patients and providers. ${ }^{47}$ However, more recent data from several sources indicate that significant respiratory depression is rare among women managed with neuraxial morphine for cesarean birth. ${ }^{25}$ This is a relevant counterpoint to our findings of frequent clinically relevant respiratory depression using systemic rather than neuraxial hydrophilic 
Table 3 Proportion of women requiring respiratory support in the first 24 hours postcesarean birth by prepregnancy BMI

\begin{tabular}{|c|c|c|c|c|c|}
\hline \multirow[t]{2}{*}{ BMI class } & $\begin{array}{l}\text { Nonobese } \\
\mathrm{BMI}<30\end{array}$ & $\begin{array}{l}\text { Class I obesity } \\
\text { BMI 30-34.9 }\end{array}$ & $\begin{array}{l}\text { Class II obesity } \\
\text { BMI 35-39.9 }\end{array}$ & $\begin{array}{l}\text { Class III obesity } \\
\mathrm{BMI} \geq 40\end{array}$ & \multirow[t]{2}{*}{$p$-Value } \\
\hline & $\begin{array}{l}(n=1,528) \\
n(\%)\end{array}$ & $\begin{array}{l}(n=321) \\
n(\%)\end{array}$ & $\begin{array}{l}(n=195) \\
n(\%)\end{array}$ & $\begin{array}{l}(n=186)^{\mathrm{a}} \\
n(\%)\end{array}$ & \\
\hline Composite respiratory event & $504(33.0)$ & $135(42.1)$ & $74(37.9)$ & $77(41.4)$ & 0.009 \\
\hline \multicolumn{6}{|l|}{ Oxygen desaturation ${ }^{\mathrm{a}}$} \\
\hline Normal & $1,087(71.1)$ & $198(61.7)$ & $135(69.2)$ & $116(62.4)$ & \multirow[t]{4}{*}{0.012} \\
\hline Mild & $404(26.4)$ & $118(36.8)$ & $56(28.7)$ & $66(35.5)$ & \\
\hline Moderate & $25(1.6)$ & $3(0.9)$ & $3(1.5)$ & $4(2.2)$ & \\
\hline Severe & $3(0.2)$ & $2(0.6)$ & $1(0.5)$ & $0(0)$ & \\
\hline \multicolumn{6}{|l|}{ Respiratory support modality } \\
\hline Cannula & $117(7.7)$ & $24(7.5)$ & $19(9.7)$ & $19(10.2)$ & 0.716 \\
\hline Nonrebreather mask & $8(0.5)$ & $0(0)$ & $0(0)$ & $1(0.5)$ & 0.782 \\
\hline CPAP & $0(0)$ & $0(0)$ & $2(1.0)$ & $3(1.6)$ & $<0.001$ \\
\hline New CPAP & $0(0)$ & $0(0)$ & $0(0)$ & $2(1.0)$ & $<0.001$ \\
\hline High respiratory support & $11(0.7)$ & $2(0.6)$ & $3(1.5)$ & $4(2.1)$ & 0.228 \\
\hline
\end{tabular}

Abbreviations: BMI, body mass index; CPAP, continuous positive airway pressure.

Note: Bold signifies statistical significance, or $p$-value $<0.05$.

${ }^{a}$ Data on oxygen desaturation was missing for nine women.

Table 4 Proportion of women requiring respiratory support in the first 24 hours postcesarean birth 24-hour opioid dose

\begin{tabular}{|c|c|c|c|c|}
\hline \multirow[t]{2}{*}{ 24-h morphine dose (mg) } & $0-90$ & 151-299 & $300+$ & \multirow[t]{2}{*}{$p$-Value } \\
\hline & $\begin{array}{l}(n=829) \\
n(\%)\end{array}$ & $\begin{array}{l}(n=721) \\
n(\%)\end{array}$ & $\begin{array}{l}(n=684) \\
n(\%)\end{array}$ & \\
\hline Composite respiratory event & $283(34.1)$ & $229(31.8)$ & $282(41.2)$ & 0.004 \\
\hline \multicolumn{5}{|l|}{ Oxygen desaturation $^{a}$} \\
\hline Normal & $567(68.4)$ & $518(71.8)$ & $454(66.4)$ & \multirow[t]{4}{*}{0.254} \\
\hline Mild & $250(30.2)$ & $187(25.9)$ & $210(30.7)$ & \\
\hline Moderate & $8(1.0)$ & $12(1.7)$ & $15(2.2)$ & \\
\hline Severe & $1(0.1)$ & $2(0.3)$ & $3(0.4)$ & \\
\hline \multicolumn{5}{|l|}{ Respiratory support modality } \\
\hline Cannula & $41(4.9)$ & $50(6.9)$ & $89(13.0)$ & $<0.001$ \\
\hline Nonrebreather mask & $1(0.1)$ & $3(0.4)$ & $5(0.7)$ & 0.149 \\
\hline CPAP & $0(0)$ & $0(0)$ & $5(0.7)$ & 0.003 \\
\hline High respiratory support & $2(0.2)$ & $3(0.7)$ & $13(1.9)$ & 0.012 \\
\hline
\end{tabular}

Abbreviation: CPAP, continuous positive airway pressure.

Note: Bold signifies statistical significance, or $p$-value $<0.05$.

${ }^{a}$ Data on oxygen desaturation was missing for seven women.

opioids. Our findings support the more recent recommendations that neuraxial opioids are not only more effective, but likely safer, than systemic opioids when used in a multimodal strategy for postcesarean analgesia. ${ }^{25,41}$ This is also consistent with revised recommendations that allow less surveillance following neuraxial hydrophilic opioids. ${ }^{41}$

Future analyses of multi-institutional datasets are needed to allow adequate power to analyze rare events, such as severe respiratory depression and maternal deaths. Such analyses would ideally include women with a wider range of total 24-hour opioid dose and more women with identified obstructive sleep apnea.

Strengths of our study include the high number of women included, which allowed for adequate statistical power in our calculations. Our hospital also did not use extended release intrathecal morphine during the time period of this study; therefore, the systemic opioid doses used in our population is higher than that is typically seen in the obstetric population. ${ }^{46}$ While this makes the study less generalizable, it does allow us to examine the impact of higher parenteral opioid 
Table 5 Predictors of the composite respiratory outcome in the first 24 hours postcesarean birth

\begin{tabular}{|l|l|l|l|}
\hline Predictor & Linear predictors estimate (SE) & OR (95\% Cl) & $\operatorname{Pr~}(>\mid \mathrm{zI})$ \\
\hline Intercept & $-1.188(0.172)$ & $0.305(0.217-0.426)$ & $<\mathbf{0 . 0 0 1}$ \\
\hline MME by unit increase of $1 \mathrm{mg}$ & $0.005(0.002)$ & $1.005(1.002-1.008)$ & 0.003 \\
\hline BMI by unit increase of $1 \mathrm{~kg} / \mathrm{m}^{2}$ & $0.062(0.021)$ & $1.063(1.021-1.108)$ & 0.003 \\
\hline Magnesium sulfate use & $0.918(0.203)$ & $2.505(1.687-3.751)$ & $<\mathbf{0 . 0 0 1}$ \\
\hline MME: BMI interaction & $-0.0004(0.0002)$ & $1.000(0.999-1.000)$ & $\mathbf{0 . 0 3}$ \\
\hline
\end{tabular}

Abbreviations: BMI, body mass index; $\mathrm{Cl}$, confidence interval; MME, morphine milligram equivalent; OR, odds ratio; SE, standard error. Note: Bold signifies statistical significance, or $p$-value $<0.05$.

doses than that are typically seen in the postcesarean population. ${ }^{46}$ Findings in other populations with less systemic opioid use may be less pronounced.

Our study also had significant limitations. First, this is a retrospective analysis using data available through the electronic medical record system and our hospital's birth reporting database with inherent limitations in the available data. Nevertheless, data from the electronic medical record does accurately reflect objective measurements entered, such as BMI and vital signs, including pulse oximetry readings. This record also accurately captures every dose of postoperative opioids administered. Our population is predominantly nonHispanic white, which is not representative of populations in other parts of our state and country. Sleep apnea was likely both underdiagnosed and underdocumented with only 16 individuals $(<1 \%)$ carrying this diagnosis in the electronic medical record. This limited our ability to assess this exposure on respiratory outcomes. Finally, the high dose of systemic opioids may have limited our ability to compare low to higher doses as the 24-hour dose was overall high for the majority of women.

\section{Conclusion}

Our study concluded that obesity, and to a lesser degree systemic opioid dose, was positively correlated with the incidence of respiratory events in the postoperative period following cesarean birth. We also detected considerably more instances of clinically significant respiratory depression among our population than has been reported among postcesarean women managed with neuraxial morphine, and we are using these results to inform changes to our postcesarean analgesia regimen. ${ }^{25}$ Our results are congruent with other investigations that have suggested a relationship between obesity and respiratory compromise in the nonobstetric population. ${ }^{12,15,29}$ More data in the form of multi-institutional studies are needed to definitively impact practice patterns. However, given our results, we assert that enhanced caution should be taken in the care of women with obesity in the postoperative period following cesarean birth.

Paper Presentation Information

Data from this study were presented as a poster presentation at the Wisconsin Association for Perinatal Care, Oshkosh, WI, April 7-9, 2019, abstract number 16.

\section{Funding}

This project was supported by the Clinical and Translational Science Award (CTSA) program, through the National Institutes of Health (NIH) National Center for Advancing Translational Sciences (NCATS), grant no. UL1TR002373 and the University of Wisconsin School of Medicine and Public Health Department of Obstetrics and Gynecology. The funding source had no role in the study design, collection, analysis or interpretation of data, writing of the report, or decision to submit the article for publication.

Conflict of Interest

None declared.

\section{Acknowledgments}

The content is the sole responsibility of the authors and does not necessarily represent the official views of the National Institutes of Health. We would like to acknowledge Walter Bredl, Ruth Hallquist, and Jonathan Garvey (employed by UnityPoint Health - Meriter) for their support and assistance with extracting data from the Epic electronic health record. We would also like to acknowledge Kathy Gollmar, Carla Griffin, and Ancilla Partners for their support and assistance with data extraction from PeriData.Net for this project (employed by UnityPoint Health - Meriter). PeriData.Net is a comprehensive birth registry maintained by Ancilla Partners, Inc. This registry provides process and outcome measure results as well as birth level data on how well a given hospital and its providers are administering quality of care before, during, and after the birthing lifecycle. We would finally like to acknowledge Robert Koehler and Emmalee Davis for assisting with the literature review and article acquisition (employed by UnityPoint Health Meriter and the University of Wisconsin-Madison, respectively).

\section{References}

1 Mamun AA, Callaway LK, O'Callaghan MJ, et al. Associations of maternal pre-pregnancy obesity and excess pregnancy weight gains with adverse pregnancy outcomes and length of hospital stay. BMC Pregnancy Childbirth 2011;11:62

2 Hartge D, Spiegler J, Schroeer A, Deckwart V, Weichert J. Maternal super-obesity. Arch Gynecol Obstet 2016;293(05):987-992 
3 Stamilio DM, Scifres CM. Extreme obesity and postcesarean maternal complications. Obstet Gynecol 2014;124(2 Pt 1):227-232

4 Fyfe EM, Anderson NH, North RA, et al; Screening for Pregnancy Endpoints (SCOPE) Consortium. Risk of first-stage and secondstage cesarean delivery by maternal body mass index among nulliparous women in labor at term. Obstet Gynecol 2011;117 (06):1315-1322

5 Magriples U, Kershaw TS, Rising SS, Westdahl C, Ickovics JR. The effects of obesity and weight gain in young women on obstetric outcomes. Am J Perinatol 2009;26(05):365-371

6 O'Dwyer V, Farah N, Fattah C, O'Connor N, Kennelly MM, Turner MJ. The risk of caesarean section in obese women analysed by parity. Eur J Obstet Gynecol Reprod Biol 2011;158(01):28-32

7 Pallasmaa N, Ekblad U, Aitokallio-Tallberg A, et al. Cesarean delivery in Finland: maternal complications and obstetric risk factors. Acta Obstet Gynecol Scand 2010;89(07):896-902

8 Bonnesen B, Secher NJ, Møller LK, Rasmussen S, Andreasen KR, Renault K. Pregnancy outcomes in a cohort of women with a preconception body mass index $>50 \mathrm{~kg} / \mathrm{m}^{2}$. Acta Obstet Gynecol Scand 2013;92(09):1111-1114

9 Mhyre JM, Riesner MN, Polley LS, Naughton NN. A series of anesthesia-related maternal deaths in Michigan, 1985-2003. Anesthesiology 2007;106(06):1096-1104

10 The American College of Obstetricians and Gynecologists. Obesity in pregnancy. Practice Bulletin No. 156. Obstet Gynecol 2015;126: e112-e126

11 Catalano PM, Shankar K. Obesity and pregnancy: mechanisms of short term and long term adverse consequences for mother and child. BMJ 2017;356:j1

12 Alvarez A, Singh PM, Sinha AC. Postoperative analgesia in morbid obesity. Obes Surg 2014;24(04):652-659

13 Lloret-Linares C, Lopes A, Declèves X, et al. Challenges in the optimisation of post-operative pain management with opioids in obese patients: a literature review. Obes Surg 2013;23(09):1458-1475

14 Nightingale CE, Margarson MP, Shearer E, et al; Members of the Working Party Association of Anaesthetists of Great Britain Ireland Society for Obesity and Bariatric Anaesthesia. Peri-operative management of the obese surgical patient 2015: Association of Anaesthetists of Great Britain and Ireland Society for Obesity and Bariatric Anaesthesia. Anaesthesia 2015;70(07):859-876

15 Oderda G. Challenges in the management of acute postsurgical pain. Pharmacotherapy 2012;32(9, Suppl):6S-11S

16 Overdyk F, Dahan A, Roozekrans M, van der Schrier R, Aarts L, Niesters M. Opioid-induced respiratory depression in the acute care setting: a compendium of case reports. Pain Manag 2014;4 (04):317-325

17 Lee LA, Caplan RA, Stephens LS, et al. Postoperative opioidinduced respiratory depression: a closed claims analysis. Anesthesiology 2015;122(03):659-665

18 Mason EE, Renquist KE, Jiang D. Perioperative risks and safety of surgery for severe obesity. Am J Clin Nutr 1992;55(2, Suppl):573S-576S

19 Hagle ME, Lehr VT, Brubakken K, Shippee A. Respiratory depression in adult patients with intravenous patient-controlled analgesia. Orthop Nurs 2004;23(01):18-27, quiz 28-29

20 Schug SA, Raymann A. Postoperative pain management of the obese patient. Best Pract Res Clin Anaesthesiol 2011;25(01):73-81

21 Gross JB, Bachenberg KL, Benumof JL, et al; American Society of Anesthesiologists Task Force on Perioperative Management. Practice guidelines for the perioperative management of patients with obstructive sleep apnea: a report by the American Society of Anesthesiologists Task Force on Perioperative Management of patients with obstructive sleep apnea. Anesthesiology 2006;104 (05):1081-1093, quiz 1117-1118

22 Blake DW, Yew CY, Donnan GB, Williams DL. Postoperative analgesia and respiratory events in patients with symptoms of obstructive sleep apnoea. Anaesth Intensive Care 2009;37(05): 720-725
23 Kessler ER, Shah M, Gruschkus SK, Raju A. Cost and quality implications of opioid-based postsurgical pain control using administrative claims data from a large health system: opioidrelated adverse events and their impact on clinical and economic outcomes. Pharmacotherapy 2013;33(04):383-391

24 Crowgey TR, Dominguez JE, Peterson-Layne C, Allen TK, Muir HA, Habib AS. A retrospective assessment of the incidence of respiratory depression after neuraxial morphine administration for postcesarean delivery analgesia. Anesth Analg 2013;117(06): 1368-1370

25 Sharawi N, Carvalho B, Habib AS, Blake L, Mhyre JM, Sultan P. A systematic review evaluating neuraxial morphine and diamorphine-associated respiratory depression after cesarean delivery. Anesth Analg 2018;127(06):1385-1395

26 Loubert C, Fernando R. Cesarean delivery in the obese parturient: anesthetic considerations. Womens Health (Lond) 2011;7(02): 163-179

27 Mace HS, Paech MJ, McDonnell NJ. Obesity and obstetric anaesthesia. Anaesth Intensive Care 2011;39(04):559-570

28 Mhyre JM. Anesthetic management for the morbidly obese pregnant woman. Int Anesthesiol Clin 2007;45(01):51-70

29 Soens MA, Birnbach DJ, Ranasinghe JS, van Zundert A. Obstetric anesthesia for the obese and morbidly obese patient: an ounce of prevention is worth more than a pound of treatment. Acta Anaesthesiol Scand 2008;52(01):6-19

30 Taylor S, Kirton OC, Staff I, Kozol RA. Postoperative day one: a high risk period for respiratory events. Am J Surg 2005;190(05): 752-756

31 American College of Obstetricians and Gynecologists. Task Force on Hypertension in Pregnancy. Hypertension in Pregnancy (Task Force on Hypertension in Pregnancy, ed.). Washington, DC: American College of Obstetricians and Gynecologists; 2013

32 The American College of Obstetricians and Gynecologists. Pregestational diabetes mellitus. ACOG Practice Bulletin No. 60 . Obstet Gynecol 2005;105:675-685

33 The American College of Obstetricians and Gynecologists. Gestational diabetes mellitus. ACOG Practice Bulletin No. 190. Obstet Gynecol 2018;131(180):49-64

34 World Health Organization. Obesity: preventing and managing the global epidemic. Report of a WHO consultation. World Health Organ Tech Rep Ser 2000;894:i-xii, 1-253

35 Nielsen S, Degenhardt L, Hoban B, Gisev N. A synthesis of oral morphine equivalents (OME) for opioid utilisation studies. Pharmacoepidemiol Drug Saf 2016;25(06):733-737

36 Centers for Disease Control and Prevention. Calculating total daily dose of opioids for safer dosage. Accessed on July 2, 2019, at: https://www.cdc.gov/drugoverdose/prescribing/guideline.html

37 American Society of Addiction Medicine. Public Policy Statement on Morphine Equivalent Units/Morphine Milligram Equivalents. 2016. Accesssed on July 8, 2020, at: https://www.asam.org/docs/ default-source/public-policy-statements/2016-statement-onmorphine-equivalent-units-morphine-milligram-equivalents. pdf?sfvrsn=3bc177c2_6\#search=\%22omemme\%22

38 von Elm E, Altman DG, Egger M, Pocock SJ, Gøtzsche PC, Vandenbroucke JPSTROBE Initiative. Strengthening the Reporting of Observational Studies in Epidemiology (STROBE) statement: guidelines for reporting observational studies. BMJ 2007;335 (7624):806-808

39 von Ungern-Sternberg BS, Regli A, Bucher E, Reber A, Schneider MC. Impact of spinal anaesthesia and obesity on maternal respiratory function during elective caesarean section. Anaesthesia 2004;59(08):743-749

40 Abouleish E. Apnoea associated with the intrathecal administration of morphine in obstetrics. A case report. Br J Anaesth 1988;60 (05):592-594

41 Bauchat JR, Weiniger CF, Sultan P, et al. Society for Obstetric Anesthesia and Perinatology Consensus Statement: monitoring recommendations for prevention and detection of respiratory 
depression associated with administration of neuraxial morphine for cesarean delivery analgesia. Anesth Analg 2019;129(02): 458-474

42 Bonner JC, McClymont W. Respiratory arrest in an obstetric patient using remifentanil patient-controlled analgesia. Anaesthesia 2012;67(05):538-540

43 Marr R, Hyams J, Bythell V. Cardiac arrest in an obstetric patient using remifentanil patient-controlled analgesia. Anaesthesia 2013;68(03):283-287

44 Fuller JD, Crombleholme WR. Respiratory arrest and prolonged respiratory depression after one low, subcutaneous dose of alphaprodine for obstetric analgesia. A case report. J Reprod Med 1987;32(02):149-151
45 Abouleish E, Rawal N, Rashad MN. The addition of 0.2 mg subarachnoid morphine to hyperbaric bupivacaine for cesarean delivery: a prospective study of 856 cases. Reg Anesth 1991;16 (03):137-140

46 Altenau B, Crisp CC, Devaiah CG, Lambers DS. Randomized controlled trial of intravenous acetaminophen for postcesarean delivery pain control. Am J Obstet Gynecol 2017;217(03):362. e1-362.e6

47 Horlocker TT, Burton AW, Connis RT, et al; American Society of Anesthesiologists Task Force on Neuraxial Opioids. Practice guidelines for the prevention, detection, and management of respiratory depression associated with neuraxial opioid administration. Anesthesiology 2009;110(02):218-230 